\title{
Transparency Meets Management: a Monitoring and Evaluating Tool for Governmental Projects
}

\author{
Celio Trois ${ }^{*}$, Daniel Weingaertner ${ }^{\dagger}$, Diego Pasqualin ${ }^{\ddagger}$, Edemir Maciel $^{\S}$, \\ Eduardo Almeida ${ }^{\text {I }}$, Fabiano Silvall, Hegler Tissot**, Luis C. E. Bona ${ }^{\dagger \dagger}$, \\ Marcos Castilho ${ }^{\ddagger \ddagger}$, Marcos Didonet ${ }^{\mathrm{x}}$ and Marcos Sunyé ${ }^{\mathrm{xi}}$ \\ Center for Scientific Computing and Free Software \\ Department of Informatics \\ Federal University of Paraná (UFPR) \\ R. Cel. Francisco H. dos Santos, 100 - Curitiba - PR - Brasil \\ Email: *celio.trois@gmail.com, †danielw@inf.ufpr.br, ${ }^{\ddagger}$ dpasqualin@inf.ufpr.br, ${ }^{\circledR}$ edemir@inf.ufpr.br,

 \\ 怙marcos@inf.ufpr.br, xdidonet@inf.ufpr.br, sunye@inf.ufpr.br
}

\begin{abstract}
The Brazilian government is maintaining several digital inclusion projects, providing computers and Internet connection to developing regions around the country. However, these projects can only succeed if they are constantly assessed; namely, the projects infrastructure deployment must be closely monitored and evaluated. In this paper, we introduce a system called SIMMC, which is currently monitoring and evaluating more than 4,500 computing devices from Brazilian digital inclusion projects. This system is innovative because, in addition to being used by the government for managing and expanding its projects, the collected data is also publicly available on a web page, allowing the citizens to follow the projects' deployment. We describe the SIMMC architecture, reporting some techniques used to optimize its data analysis processes, and describe how the information acquired and presented by the system has been used to enable public administration overhaul and improve efficiency on the project management, as well as its strategic use for security, theft, and defrauding.
\end{abstract}

\section{INTRODUCTION}

Digital Inclusion is imperative to the whole process of bridging the digital divide and fomenting a digital cohesion that secures opportunity through the Internet, mobile services and computerization of processes, bringing in a new era of a connected nation and using technology better on behalf of citizens and communities [1]. In this context, the Brazilian government is investing in digital inclusion projects, deploying computers and Internet connectivity in remote areas where broadband service does not exist. Three of the main ongoing projects are: i) Gesac ${ }^{1}$ offers free Internet connection to schools, health units, indigenous villages, and quilombos ${ }^{2}$. ii) The Digital Cities $^{3}$ implements network infrastructure for connecting government buildings and also affords free Internet access points in public spaces. iii) The Telecentres ${ }^{4}$ provides free public access to computers connected to the Internet.

\footnotetext{
${ }^{1}$ Gesac project (Portuguese only): http://www.mc.gov.br/gesac.

${ }^{2}$ Quilombos are communities founded in colonial Brazil, organized by fugitive slaves and located in inaccessible areas.

${ }^{3}$ Digital Cities project (Portuguese only): http://www.mc.gov.br/ cidades-digitais.

${ }^{4}$ Telecentres project (Portuguese only): http://www.mc.gov.br/telecentros.
}

These are non-profit projects fostering social and economic development, reducing social exclusion and promoting Internet connection for Brazilian developing regions.

To determine if the projects' outcomes are being achieved it is necessary to perform regular measurement of key performance indicators [2]. Usually, the assessment is made by a government official who goes to the locality and ascertains the conditions and use of devices or services. In a continental country like Brazil, where there are thousands of scattered locations, this procedure is time-consuming and expensive, so a sampling procedure must be adopted. Evaluating by sampling allows the program to be monitored but does not allow precise control of each $\mathrm{PoP}^{5}$.

The requirements of the projects on efficiency and transparency obligate the government to continuously improve the management practices. As demands for accountability and real results have increased, there is an attendant need for enhanced results-based monitoring and evaluation (M\&E) of policies, programs, and projects [3]. M\&E is a powerful public management tool that can be used to improve the way governments achieve results [4]. The implementation of an M\&E system allows effective assessment control on a timely basis, identifying and reporting deficiencies and highlighting necessary corrective actions, but also pose some main challenges:

1) Challenge 1. Usually, the data is acquired from thousands of non-standardized devices scattered all over the country, sometimes with limited Internet connectivity.

2) Challenge 2. This type of system receives huge streams of raw data which must be efficiently transformed to useful indicators.

3) Challenge 3. The system must provide an robust and intuitive graphical interface supporting multiple simultaneous accesses.

\footnotetext{
${ }^{5} \mathrm{~A}$ PoP is a physical location (schools, telecentres, quilombos) where the devices (computers and routers), financed by the government, have been installed to provide digital inclusion and Internet access.
} 
So, the Brazilian Ministry of Science, Technology, Inovation and Communications (MCTIC) established a partnership with the $\mathrm{C}_{3} \mathrm{SL}^{6}$ research group for developing an M\&E system able to deal with these challenges. This system was called SIMMC $^{7}$, and it was designed to be efficient and robust on providing the necessary information for the government projects assessment. The SIMMC is free software, and its architecture is composed of three main modules: Data Collection, Storage, and Visualization.

To combat the Challenge 1, we first implemented different approaches for gathering the information from the various types of devices. Then, to increase the scalability of the Collection Module, we developed mechanisms to randomize the data acquirement process. Big data analysis methods were used for tackling the Challenge 2. For implementing the Storage Module, we used Staging Area, Fact Tables, and Data Marts, common Data Warehouse techniques [5]. Furthermore, for speeding up the data analysis process, we implemented optimizations such as tables de-normalization and efficient methods for updating the Data Marts. Finally, Challenge 3 was mitigated with a consistent way to explore the data. Users can navigate through charts, reports, and maps, three complementary forms of visualizing information presented by the same logic, starting from a country view, moving forward to regions, states, cities and finally the PoPs itself.

An important caveat regards the data transparency; all data collected from SIMMC is publicly available to citizens on a website. The system won a competition ${ }^{8}$ promoted by the Brazilian government in the category "Promoting Active or Passive Transparency." To our knowledge, this is the first Brazilian M\&E system to open the monitored data publicly.

The system is gathering information on availability, hardware and software inventory, and network bandwidth usage, currently receiving more than 1.8 million new records per day, totaling around 1.2 billion entries in its database. It monitors over forty-five hundred devices spanning over 2,342 Brazilian cities, as shown in Table I. During the three years this system is operating, it has demonstrated that it can be efficient for assisting the management of digital inclusion projects. So, we believe that the SIMMC case study can be successfully applied to any governmental initiative that needs to be monitored and evaluated.

This paper is organized as follows. First, we present the digital inclusion initiatives and their monitoring requirements, in Section II. SIMMC architectural modules and their design choices are detailed in Section III. A set of representative examples of how the SIMMC is being used to assist the project management is reported and discussed in Section IV. The

\footnotetext{
${ }^{6} \mathrm{C} 3 \mathrm{SL}$ website (Portuguese only): http://www.c3sl.ufpr.br/.

${ }^{7}$ SIMMC website (Portuguese only): http://simmc.c3sl.ufpr.br/.

${ }^{8}$ The result is available at (Portuguese only): http://www.cgu.gov.br/ sobre/institucional/concursos/concurso-de-boas-praticas/edicoes-anteriores/ 3o-concurso-de-boas-praticas-2015/.

${ }^{9}$ Active transparency occurs when public entities disseminate information on their own initiative, whereas passive transparency information is given when demanded.
}

future directions are shown in Section V and finally, Section VI presents the conclusion.

\section{Digital Inclusion Initiatives}

Digital inclusion provides citizens the expansion of citizenship, integration into the labor market, and formal and sociocultural education [6], and it depends on five main factors [7]: i) the existence of a physical transmission infrastructure; ii) the availability of devices connected to the Internet; iii) the provision of computing and Internet courses; iv) the support for citizens intellectual empowerment and social integration; and $v$ ) the production of specific contents adapted to different population segments.

For providing these factors, the Brazilian government, through the MCTIC, is funding projects to afford digital inclusion for Brazilian citizens:

1) The Telecentres is a non-profit project, providing digital inclusion places, called telecentres, with free public access to computers connected to the Internet. The telecentres also offer several courses and activities, according to the local community needs, acting as a space for integration, culture, and leisure.

2) The Gesac project focuses primarily on communities with low HDI without commercial Internet, such as villages in the middle of Amazon Forest. It provides free Internet connection to schools, health units, indigenous villages, border crossings, telecentres, and quilombos.

3) The Digital Cities project improves efficiency in public management, affording better attendance to citizens and city development. It implements network infrastructure for connecting government buildings, provides egovernment applications, and offers free Internet access points in public spaces such as squares, parks, and bus stations.

For measuring the success of these projects, it is essential to receive feedback at each step of their implementation process. So, the importance of using an M\&E system for allowing the government to be on top of any problems, to oversee any corrective measures, and to prevent deficiencies from being overlooked. [8].

\section{A. Monitoring Requirements}

Monitoring and evaluation (M\&E) systems are being used to help the governments to track the progress and demonstrate the impact of a given project, program, or policy. In Latin America, it is increasing the use of $M \& E$ systems in the public sector, enabling transparency and effectiveness of government actions [9]. These systems are instruments for monitoring

TABLE I

NUMBER OF POPS MONITORED PER PROJECT AND DISTRIBUTION AMONG BRAZILIAN CITIES (5,570 IN TOTAL).

\begin{tabular}{lllll} 
& Gesac & Telecentres & Digital Cities & TOTAL \\
\hline PoPs & 3559 & 430 & 472 & 4461 \\
Cities & $1981(36 \%)$ & $616(11 \%)$ & $64(1 \%)$ & $2342(42 \%)$
\end{tabular}


TABLE II

PROJECT REQUIREMENTS FOR VIEWING THE INDICATORS

\begin{tabular}{lcccc}
\hline Project & Avail. & Invent. & $\begin{array}{c}\text { Invent. } \\
\text { Change }\end{array}$ & $\begin{array}{c}\text { Net. } \\
\text { Usage }\end{array}$ \\
\hline Gesac & $\mathrm{C} / \mathrm{R}$ & & $\mathrm{C} / \mathrm{R}$ \\
Digital Cities & $\mathrm{C} / \mathrm{R}$ & & & $\mathrm{C}$ \\
Telecentres & $\mathrm{C} / \mathrm{R}$ & $\mathrm{C} / \mathrm{R}$ & $\mathrm{C} / \mathrm{R}$ & $\mathrm{C}$ \\
\hline \multicolumn{4}{r}{ Legend: $C=$ Chart $/ R=$ Report }
\end{tabular}

infrastructures, measuring indicators, improving management, and promoting accountability of public spending.

Each Brazilian government project posed different measurement requirements, and the $\mathrm{M} \& \mathrm{E}$ system should be aware of these peculiarities. For the Telecentres project, the government is providing computers, routers, and links, needing to assess information about their status and use. For Gesac and Digital Cities projects it is funding just routers and links. For routers, the MCTIC has demanded information on availability and network usage, and for computers, in addition to these indicators, hardware and software had to be monitored. The system should provide reports and charts on availability, inventory, and inventory changes; besides that, the network usage should be seen as a chart. These requirements are summarized in Table II.

Based on these requirements, through an initiative funded by the MCTIC, the C3SL Labs has developed the SIMMC, a $\mathrm{M} \& \mathrm{E}$ system for automatically and continuously monitoring the government projects. The C3SL already had experience in developing monitoring systems for computer grids for educational purposes [10] and also for about 150,000 computers in a project with Ministry of Education named PROINFODATA [11]. For developing SIMMC, we had to consider the heterogeneous environment promoted by the different technologies involved in the monitored projects and the lack of standard regarding the operating system and tools installed in the computers of the telecentres. Furthermore, we had to use big data analytic techniques for making the system scalable to ingest a huge amount of data and to allow data visualization through a public website supporting thousands or simultaneous accesses. In addition, it had to deal with low quality and intermittent links at the endpoints.

\section{SIMMC ARCHITECTURE}

The SIMMC ${ }^{10}$ is open-source and free, under the terms of the GNU General Public Licence (GPL) [12]. It was deployed in late 2014 and currently it is monitoring around 4,500 PoPs. The system was designed as three main modules: Data Collector, Storage, and Visualization. Figure 1 shows an overview of SIMMC architecture, showing its main components and the interconnection among its modules.

The Data Collector module is responsible for measuring and collecting information from PoPs' devices. This information is sent to the SIMMC servers by the Collector Agent (CA) or through SNMP [13]. Once received, this information is

\footnotetext{
${ }^{10}$ SIMMC source code: https://gitlab.c3sl.ufpr.br/minicom/SIMMC.
}

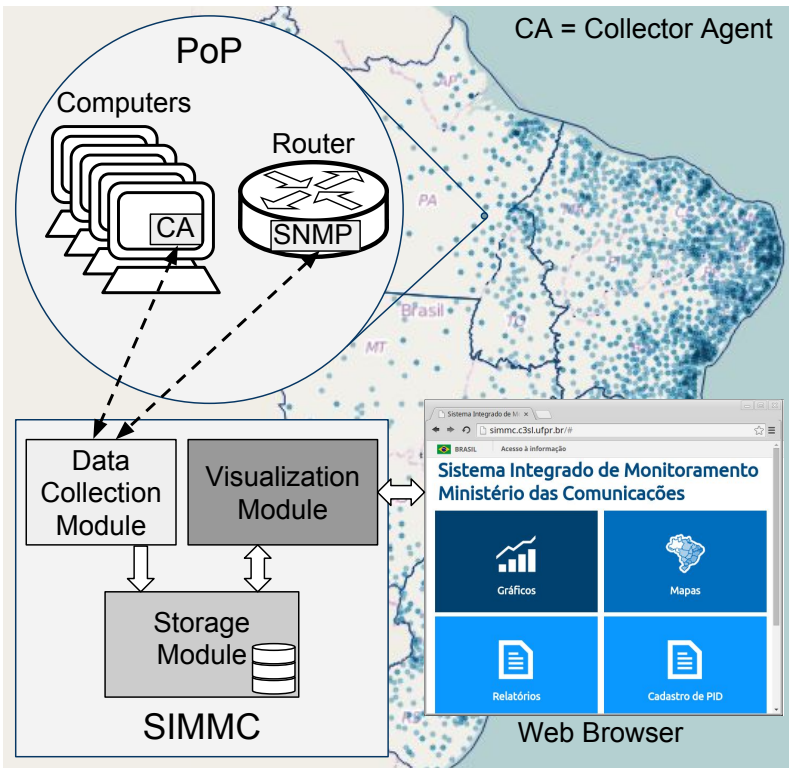

Fig. 1. SIMMC architecture overview.

stored in the Storage module. All SIMMC information can be accessed via web browser, through the Visualization module. The following sections describe the modules implementation details.

\section{A. Data Collector Module}

The Data Collector module is responsible for acquiring information from PoPs and sending it to the Storage module. As a heterogeneous environment is monitored, the Data Collector was designed to be aware of each category of device, concerning their technology and connectivity limitations.

For Telecentres, the software Collector Agent must be installed on computers to enable monitoring; the first time it is executed, the user must select the PoP where the computer is located. The Collector Agent is available for any major Linux distribution and also Windows. Its implementation complies with the following requirements: (i) it should be lightweight to avoid overloading the computer's CPU, (ii) it should use few network bandwidth to avoid burdening the servers and links, and (iii) it should be possible to remotely update it. The agent is configured to collect, every five minutes throughout the day, indicators on hardware (CPU, RAM memory, and hard disk), software (installed Operating System), and network usage. However, new indicators may be included.

Routers (Gesac and Digital Cities) are monitored via SNMP; so, every five minutes the Data Collector module sends SNMP requests to all routers to collect the network traffic. Each router responds the total number of downloaded and uploaded bytes since it was started. The module computes the difference between two consecutive requests to get the network 
traffic in a given interval ${ }^{11}$.

Due to the scalability requirements, some tricks were implemented in this module to reduce the load and the network footprint on the SIMMC servers. First, for the Telecentres, the Collector Agent acquires data every five minutes, but sends it only once a day at a randomly chosen time. Second, for monitoring the routers, an parallel Python script sends thousands of asynchronous SNMP requests every five minutes at the time, later parsing and inserting the SNMP responses into the database during the five-minute interval. Finally, both the Collector Agent and the Python script provide a failover mechanism, ensuring that even if the Storage Module is offline, data will be stored and inserted as soon as it becomes available again.

\section{B. Storage Module}

Currently, this module is responsible for receiving more than 1.8 million new records per day, totaling about 1.2 billion entries. It has been implemented using a traditional data warehouse (DW) [5] modeling over a relational database (PostgreSQL). To meet the big data analytics scalability requirements, this module used some DW techniques, such as Staging Area, Fact Tables, and Data Marts. The Staging Area is composed of temporary tables optimized for data insertion. Fact Tables are the primary tables where each record represents a measurement for a particular indicator in a given time. Data Marts are subsets of the Fact Tables, designed to increase the Visualization module overall performance by generating views for common reports and charts.

Figure 2 displays the Storage module data flow. The Data collector module inserts the gathered information into the Staging Area. The consolidation process is scheduled to run overnight, and is responsible for validating data from Staging Area, updating the historical records (Fact Network Usage and Fact Inventory), and creating the Data Marts. Malformed or

\footnotetext{
${ }^{11}$ For the SNMP communication to work, every router needs a fixed IP address and the network must have a standard way to provide access to the SNMP tables. These requirements might impact the complexity of the network deployment, so contracted ISPs should be aware of the monitoring requirements beforehand, otherwise further expenditure will likely be necessary.
}



Fig. 2. Storage module data flow.

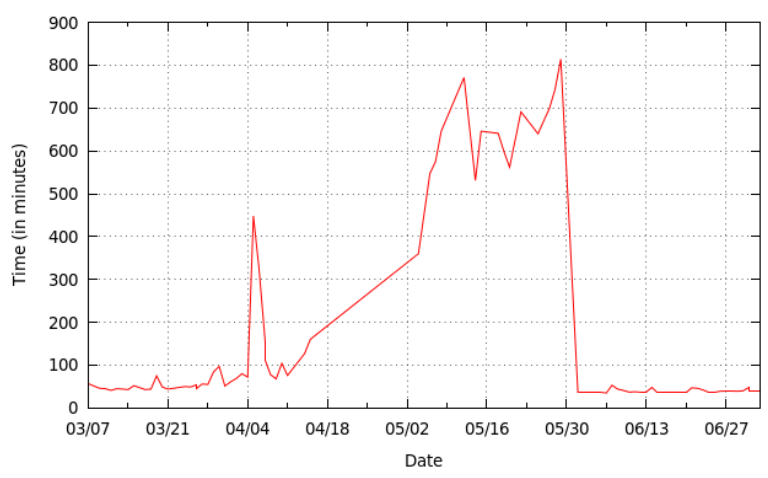

Fig. 3. Time for executing the consolidation process once a day for the period of four months.

invalid data is stored in the Rejected table, allowing developers to further analyze it and identify possible issues in the Data collector module.

The time required for data consolidation can grow as fast as data is accumulated. An initial version of this consolidation process presented scalability problems. As it can be seen in Figure 3 , there is a peak (05/30) where the consolidation time took nearly 13 hours to complete. However, the amount of data collected daily from $04 / 18$ to $05 / 30$ did not increase enough to justify the steep climb. To tackle this scalability problem, the consolidation process was modified, and two strategies to speed up the data analysis were applied. First, denormalization was used for speeding up queries by reducing the number of table joins necessary for grouping data for aggregated queries [14]. The second modification that had a significant impact on consolidation time was to only update Data Marts instead of regenerating them entirely every time [15], as traditional DW modeling would require. The optimized process reduced the consolidation time to near 40 minutes.

\section{Visualization Module}

All collected and stored indicators can be visualized in a responsive website via three distinct and complementary methods: i) maps provide a geographical overview of the PoPs distribution, ii) charts exhibit a summarization of collected information, and iii) reports show the information in details.

Visualization through maps allows getting an overall view of projects deployment. The map shown in Figure 1 was acquired from SIMMC Visualization Module; it shows all monitored PoPs, represented by blue dots. The regions with higher concentrations are shown in dark blue; whereas areas with low-density, the dots appear isolated in light blue. The module allows freely moving the map, as well as change its zoom level to visualize the entire country, regions, states, cities, and neighborhoods. The PoPs can be clicked, and their details are displayed.

Similarly to the maps, the chart visualization allows zoom levels on country, regions, states, and cities. An example of a chart showing the availability of telecentres in South Region of 


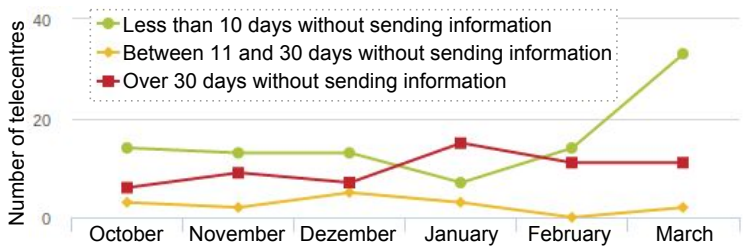

Fig. 4. Last six months availability history chart of telecentres in South Region of Brazil.

Brazil is presented in Figure 4. Zooming into the city level, when clicking a PoP, a report with detailed information is exhibited.

Although this module presents the information publicly open, there is also a restricted area used by the administration to register new PoPs, visualize sensitive data, and configure alerts. The alerts can be scheduled to send e-mails highlighting some unusual situations, such as PoPs offline for a long period of time or a computer inventory change.

\section{Management with SIMMC}

The M\&E of the digital inclusion projects through SIMMC enabled the government to assess overall aspects, such as observing their deployments, planning expansions, and tracking updates. Moreover, specific issues can also be identified by observing the indicators, in this case the network usage, availability and inventory change. Throughout this section, we present some examples of how SIMMC is being used to improve the projects management.

\section{A. Project Deployment and Expansion}

The deployment of government projects is regularly monitored by SIMMC by keeping track of the pace of new installations. Figure 5 presents the number of PoPs and daily average bandwidth usage evolution since SIMMC was deployed. Until November 2014, only Telecentres and some Digital Cities have been registered in SIMMC, but in December, the Gesac project started being monitored, including over 2,500 PoPs.

Another substantial increase in the number of PoPs is perceived in March 2016. Until February, only Gesac PoPs with satellite links were being monitored; in this month, the PoPs with terrestrial links were included, adding to the system more than 900 new PoPs. The MCTIC sometimes requested

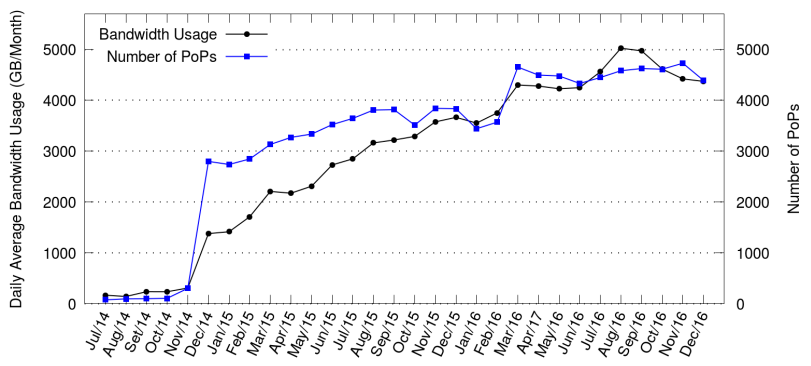

Fig. 5. Project deployment total evolution of number of PoPs and total bandwidth usage.
TABLE III

COMMON ISSUES AND CORRESPONDING ACTIONS.

\begin{tabular}{ll}
\hline Issue & Action \\
\hline Low network usage & $\begin{array}{l}\text { Identify whether the PoP is not being used or } \\
\text { the network provider is not delivering the proper } \\
\text { bandwidth (more details on section IV-B) }\end{array}$ \\
Inventory change & $\begin{array}{l}\text { Contact the PoP local administrator } \\
\text { Release payment to company responsible for local } \\
\text { New PoP contact }\end{array}$ \\
PoP not available & \begin{tabular}{l} 
Contact PoP and Internet provider \\
\hline
\end{tabular}
\end{tabular}

PoPs to be removed; this explains the reductions in the number of PoPs. The daily average network bandwidth usage increases proportionally to the number of PoPs. Currently, the average network usage is slightly less than $4 \mathrm{~TB}$ per day, totaling more than $100 \mathrm{~TB}$ of aggregate bandwidth per month.

When new computers and routers are being installed in the PoPs, their availability and inventory are shown in SIMMC. This is perceived in the system through availability history chart (Figure 4), where it is possible to see that, from February to March, there was an increase of approximately 20 new telecentres in the South Region of Brazil. Availability history charts display the projects evolution, allowing the MCTIC to trace and to program expansions.

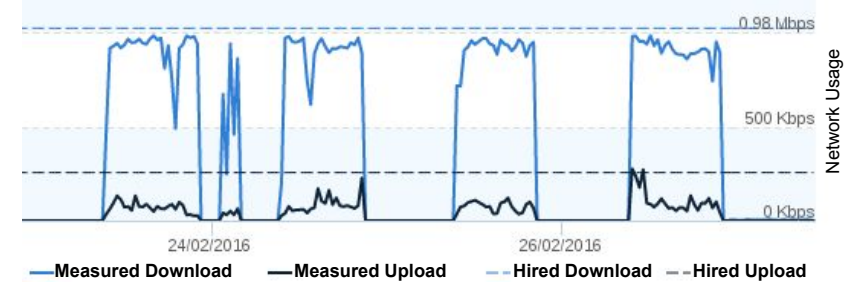

Fig. 6. Chart displaying network usage when observed bandwidth gets closer to the contracted bandwidth.

The SIMMC information is being used to define which PoPs should earn new devices. For instance, to obtain new computers, the Telecentres should maintain $70 \%$ of existing computers in operation, with availability greater than $80 \%$. The link bandwidth expansion can also be planned by observing the network usage charts. For example, in Figure 6, it is possible to see long periods of network usage near to the contracted bandwidth, which can be interpreted as link saturation. On the other hand, the Gesac project states that if a connection is not used for three months, the PoP must be deactivated, and the devices and links relocated. Furthermore, whenever it is necessary to perform any software or hardware upgrade, the SIMMC can assist tracking these updates through inventory change charts and reports. Table III summarizes common issues and correspondent actions that can be taken by MCTIC.

\section{B. Security, Theft, and Defrauding Issues}

Once the government is providing computers for public use, some security threats should be considered, for example, computer virus, botnets, and denial of service. The network usage indicator collects inbound and outbound traffic (in 
TABLE IV

SUMMARY OF POSSIBLE SCENARIOS WHEN EVALUATING NETWORK USAGE. MEASUREMENTS ARE PERFORMED EVERY FIVE MINUTES, SO A PERIOD OF 20 MINUTES CONSISTS OF FOUR MEASUREMENTS, WHICH WE CALL A PLATEAU. USAGE IS A PERCENTAGE OF THE TOTAL CONTRACTED BANDWIDTH.

\begin{tabular}{l|l|l|} 
Period Usage & $>=90 \%$ & $<90 \%$ \\
\hline$>=20 \mathrm{~m}$ & High Usage & ISP failing to deliver bandwidth \\
\hline$<20 \mathrm{~m}$ & OK & Low Usage \\
\hline
\end{tabular}

bytes), as well as the number of sent and received packets. An excessive number of small packages may indicate that the computer is infected with some malware.

The network usage charts can also be used to verify if the supplier is really providing the contracted bandwidth. This is particularly noticeable by observing the network usage peaks and identifying whether they are close to the contracted bandwidth. If the peaks have a steady behavior (a plateau), but they are not close to the contracted bandwidth line, there is an indication that the bandwidth is not being correctly supplied.

Currently, there is no way to artificially generate traffic in the PoP to saturate the link and properly measure the bandwidth, so the plateau detection is implemented as an estimation. First, we place each measured network traffic into named intervals. For instance, a measured inbound traffic between $1000 \mathrm{Kbps}$ and $900 \mathrm{Kbps}$ would be placed on interval $A$, while another measurement between $899 \mathrm{Kbps}$ and $800 \mathrm{Kbps}$ would be placed on interval $B$, and so on. The longer the sequence of measurements in the same interval, the more likely it indicates a plateau. A PoP with no plateaus is possibly not regularly using the provided bandwidth, which could therefore be downgraded (see Figure 7 for an example), and if we find plateaus for a PoP, but they never reach at least $90 \%$ of the contracted bandwidth, we consider it as an indication that the ISP is not properly delivering the contracted bandwidth (see Figure 8). Table IV display the thresholds used to decide among possible scenarios for each PoP. This algorithm is executed every month, and the last run issued a list of 1,380 PoPs with low network usage and 23 cases where the ISP might not be delivering the contracted bandwidth.

Brewer et al. [16] have studied the challenges of doing technological research in developing regions; they observed that theft and tampering is a cultural problem and a major challenge. Monitoring the computers inventory changes allows identifying these issues. Figure 9 presents a report where the

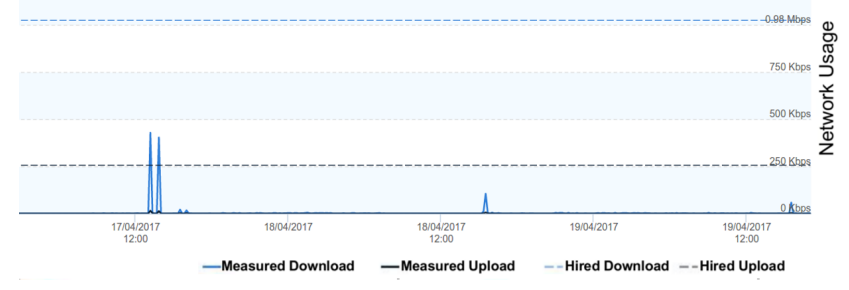

Fig. 7. An example of a PoP with low network usage.

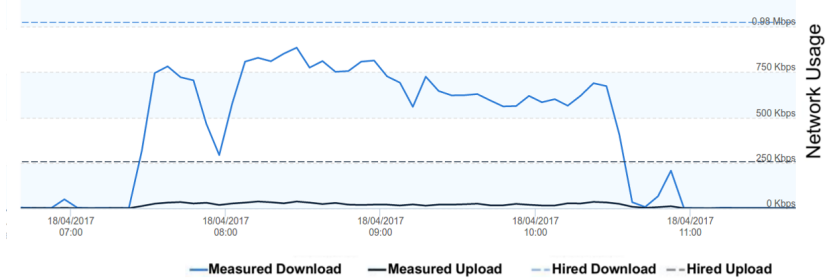

Fig. 8. An example of a plateau not reaching the contracted bandwidth, suggesting that the ISP might not be properly delivering it.

amount of memory decreased from $3.62 \mathrm{GiB}$ to $1.71 \mathrm{GiB}$ in a particular computer, so the MCTIC can investigate why there was a reduction in that computer memory. Since the monitoring started, fifty four similar cases were detected, corresponding to $7.6 \%$ of the total number of telecentres.

\begin{tabular}{ccccc|c|}
\hline MAC Address & $-00: 27: 13: a e: 18: 02$ & & & \\
05/02/14 & Ubuntu 12.04.4 LTS & $\begin{array}{l}\text { Intel(R) Core(TM) i5 CPU } 650 \\
\text { @ 3.20GHz }\end{array}$ & $3.62 \mathrm{GiB}$ & $465 \mathrm{~GB}$ \\
07/08/14 & Ubuntu 12.04.4 LTS & $\begin{array}{l}\text { Intel(R) Core(TM) i5 CPU 650 } \\
\text { @ 3.20GHz }\end{array}$ & 1.71 GiB & $465 \mathrm{~GB}$ \\
& & &
\end{tabular}

Fig. 9. Inventory change report showing a reduction in a computer memory.

These examples are not exhaustive, but they show some advantages of how monitoring the infrastructure can be useful to assist project management.

\section{FUtURE DiRECTIONS}

We are working on a generalization of this $M \& E$ platform in the following directions. i) Easy expanding: in the current version, to monitor new projects or add new features, it is necessary to change the storage structure. We plan to migrate to a more flexible database proven to be viable for analytics, such as MongoDB [17], possibly implementing a Polystore [18] solution that could provide both flexibility and fast analytics performance. ii) Focus on social aspects: we intend to allow importing open government information, such as social indicators, which could be used to enable the development of third-party software based on SIMMC data, and provide means to identify whether areas more in need of digital inclusion are actually being covered by the projects. iii) Data analysis: in the current version, the data analysis is fixed, restricted to those defined in the system. We want data analysis to be flexible, allowing administrators with no programming skills to include new metrics in the system.

\section{CONCLUSION}

In this paper, we presented a case study and implementation of the SIMMC; an open-source and free M\&E system that is allowing the Brazilian government and citizens to continually assess digital inclusion projects. The system currently acquires data from more than 4,500 computers and routers scattered in different locations in Brazil, and processes over 1.8 million new records per day, totaling around 1.2 billion entries in its database. This data has been used to generate multiple indicators that can be visualized as maps, charts, and reports. 
The successful deployment of this system is important to consolidate the relevance of data analytics as a tool for assessing government initiatives. Moreover, it is publicly available to the citizens, promoting transparency in governmental actions. We have shown the system architecture, exposing and discussing how the SIMMC is helping the Brazilian MCTIC to monitor and manage its projects.

In addition to the social importance of the project, it raised different research challenges related to data analytics. The first one was the data collection components, since the system needed to receive and process data from computers in different parts from Brazil, very often in poorly served populations. The second challenge was the choices for speeding up the data analytics process, due to the large amount of generated records, and the last was to provide an effective web interface to facilitate the data visualization. Also, there are still some issues related to the generalization of the system for use in different environments and the flexibility of the data analysis, which we intend to solve through a Polystore solution.

Finally, while open data initiatives are becoming common, we advocate that we should advance more in the big data analysis and integration of several indicators to produce useful public information for the population and governments.

\section{REFERENCES}

[1] K. Alamelu, "Digital inclusion-a conceptual framework," International Journal of Advanced Research in Management and Social Sciences, vol. 2, no. 12, pp. 228-248, 2013.

[2] A. P. Chan and A. P. Chan, "Key performance indicators for measuring construction success," Benchmarking: an international journal, vol. 11, no. 2, pp. 203-221, 2004

[3] J. Z. Kusek and R. C. Rist, Ten steps to a results-based monitoring and evaluation system: a handbook for development practitioners. World Bank Publications, 2004.

[4] P. Crawford and P. Bryce, "Project monitoring and evaluation: a method for enhancing the efficiency and effectiveness of aid project implementation," International journal of project management, vol. 21, no. 5, pp. $363-373,2003$.

[5] R. Kimball and M. Ross, The data warehouse toolkit: the complete guide to dimensional modeling. John Wiley \& Sons, 2011.

[6] S. A. da Silveira, "Inclusão digital, software livre e globalização contrahegemônica," Software Livre e Inclusao Digital-Organizadores: Sergio Amadeu de Silveira e Joao Cassino, Sao Paulo: Conrad, vol. 7, p. 11, 2003.

[7] B. Sorj, Brasil@ povo.com: a luta contra a desigualdade na Sociedade da Informação. Zahar, 2003.

[8] D. P. Slevin and J. K. Pinto, "The project implementation profile: new tool for project managers," Project management journal, vol. 7, no. 4, pp. 57-70, 1986.

[9] N. Cunill Grau and S. Ospina Bozzi, "Fortalecimiento de los sistemas de monitoreo y evaluación (m\&e) en américa latina," Caracas: Banco Mundial/CLAD, 2008.

[10] Anonymous, "Details omitted for double-blind reviewing." in Proceedings of the Second Latin American Grid (LAGrid08), 2008.

[11] _ , "Details omitted for double-blind reviewing." in Open Source Software: Mobile Open Source Technologies. Springer, 2014, pp. 226229.

[12] F. S. Foundation, "Gnu General Public License," 2007. [Online]. Available: lurl\{http://www.gnu.org/licenses/gpl-3.0.en.html\}

[13] J. D. Case, M. Fedor, M. L. Schoffstall, and J. R. Davin, "Simple network management protocol (snmp)," Internet Requests for Comments, RFC Editor, STD 15, May 1990, http://www.rfc-editor org/rfc/rfc1157.txt. [Online]. Available: http://www.rfc-editor.org/rfc/ rfc1157.txt
[14] J. A. Hoffer, M. Prescott, and F. McFadden, Modern Database Management (7th Edition). Upper Saddle River, NJ, USA: Prentice-Hall, Inc., 2004.

[15] I. S. Mumick, D. Quass, and B. S. Mumick, "Maintenance of data cubes and summary tables in a warehouse," in ACM Sigmod Record, vol. 26 , no. 2. ACM, 1997, pp. 100-111.

[16] E. Brewer, M. Demmer, M. Ho, R. Honicky, J. Pal, M. Plauche, and S. Surana, "The challenges of technology research for developing regions," IEEE Pervasive Computing, vol. 5, no. 2, pp. 15-23, 2006.

[17] Anonymous, "Details omitted for double-blind reviewing," in Proceedings of the 20th International Database Engineering \& Applications Symposium. ACM, 2016, pp. 224-229.

[18] J. Duggan, A. J. Elmore, M. Stonebraker, M. Balazinska, B. Howe, J. Kepner, S. Madden, D. Maier, T. Mattson, and S. Zdonik, "The bigdawg polystore system," ACM Sigmod Record, vol. 44, no. 2, pp. 11-16, 2015. 